\title{
Characterization of the contributions of Hp-MMP 9 to the serum acute phase protein response of lipopolysaccharide challenged calves
}

Charles A Hinds ${ }^{1,4}$, Andrew J Niehaus ${ }^{1}$, Christopher Premanandan ${ }^{2}$, Paivi J Rajala-Schultz ${ }^{3}$, Donald M Rings ${ }^{1}$ and Jeffrey Lakritz ${ }^{1 *}$

\begin{abstract}
Background: Bovine respiratory disease (BRD) is a costly feature of modern cattle production. Early and accurate detection of BRD may prove useful in the successful management of this disease. The primary objective of the study was to define the time course of covalent complexes of neutrophil, haptoglobin ( $\mathrm{Hp}$ ) and matrix metalloproteinase 9 (Hp-MMP 9) in serum after intravenous lipopolysaccharide (LPS) in comparison to traditional markers. Our hypothesis was that serum concentrations of neutrophil Hp-MMP 9 provides information distinct from traditional acute phase protein markers. To characterize the neutrophil responses to lipopolysaccharide (E. coli; O111:B4; $2.5 \mu \mathrm{g} / \mathrm{kg}$ body weight), nine healthy, Jersey calves (65-82 days of age; $74.5 \pm 13.1 \mathrm{~kg}$ ) were challenged and physiologic parameters, peripheral blood cell counts and serum cortisol (C), Hp-MMP 9, Hp, alpha, -acid glycoprotein (AGP), serum amyloid A (SAA) were obtained starting 24 hours before to 96 hours post-LPS challenge.
\end{abstract}

Results: Physiologic parameters (temperature, pulse, respiratory rate) and attitude assessed at each time point indicated that LPS challenge resulted in rapid onset of depression, tachypnea, leukopenia, neutropenia and lymphopenia within 1 hour. Serum C concentrations were significantly increased by 1 hour post-LPS. Serum Hp-MMP 9 complexes were detectable in serum by 0.5 hours and peaked at $16 \mathrm{~h}$, serum total $\mathrm{Hp}$ remained $<10 \mu \mathrm{g} / \mathrm{mL}$ until 8 hours post LPS infusion and were significantly greater than baseline by 12 hours post-LPS infusion. Serum amyloid A concentrations increased significantly by 8 hours post LPS. Serum concentrations of AGP increased significantly by 16 hours post LPS. Serum concentrations of Hp, SAA and AGP remained significantly greater than baseline out to 96 hours post-LPS. The total systemic exposure to traditional makers is significantly greater than from Hp-MMP 9

Conclusion: Using a well described model for acute phase protein responses, the data demonstrate that serum neutrophil Hp-MMP 9 complexes appear sooner and decline more rapidly than other acute phase proteins (APP). Since Hp-MMP9 is stored pre-formed, it provides information specifically addressing the LPS-induced activation of bovine neutrophils. Contributions of Hp-MMP 9 to the serum acute phase protein response may provide useful information, independent of hepatic responses, in diagnosis of acute inflammation.

Keywords: Bovine, Neutrophil, Haptoglobin-MMP 9 complexes, Acute phase response, Cortisol

\footnotetext{
* Correspondence: Lakritz.1@osu.edu

'Department of Veterinary Clinical Sciences, College of Veterinary Medicine,

The Ohio State University, 601 Vernon L Tharp Street, Columbus, Ohio 43210,

USA

Full list of author information is available at the end of the article
} 


\section{Background}

Bovine respiratory disease (BRD) and other acute inflammatory diseases have major impacts on livestock productivity. Recent reports indicate the incidence of BRD morbidity in large feedlots is approximately $5-11 \%$ and mortality attributed to BRD is approximately $0.6-1.1 \%$ [1]. However, $10 \%$ morbidity of received animals approximates 1 million head and $1 \%$ mortality is $>10,000$ head [2,3]. While there is some fluctuation in rates of disease, the incidence of BRD remains relatively constant despite application of thoughtful management decisions, development of newer pharmaceutical therapies and biological preventatives. Accurate and early diagnosis of diseases requiring administration of therapeutic agents would be beneficial to cattle industries.

Under experimental and field conditions, the use of APP to detect animals requiring treatment and animals developing lung lesions is useful. For example, haptoglobin $(\mathrm{Hp})$ responses to inflammation in cattle have been evaluated in acute bronchopneumonia [4-7], acute rumen acidosis [8], coliform mastitis [9,10], hepatic lipidosis [11], and transport stress [12,13]. Serum concentrations of $\mathrm{Hp}$ in acutely ill cattle increase ( $>100$-fold) reaching maximum concentrations between 48 and 96 h; [14-17] however, serum Hp appears to be a better indicator of clinical responses of calves with BRD to intervention than as a diagnostic for morbidity $[5,18]$. As the response of a particular APP demonstrate tremendous species and temporal differences, the gradual increase in serum concentrations of Hp over 24-48 hours, while dramatic, appear perhaps less sensitive than other APP in diagnosis of acute disease $[1,14]$. Other acute phase proteins, such as serum amyloid A (SAA) and alpha 1 acid glycoprotein (AGP) have also been studied in cattle undergoing LPS-challenge and experimental or naturally occurring disease $[1,14,19,20]$. Several studies indicate that LPS - challenge or experimental bacterial infection elicited earlier increases in serum SAA concentrations, suggesting SAA is more sensitive than $\mathrm{Hp}$ due to more rapid production and release $[1,14,19,20]$. Likewise, studies evaluating AGP after experimental LPS-challenge and $M$. hemolytica A1-challenge demonstrate more marked increases in serum concentrations of $\mathrm{Hp}$ and AGP after live bacterial challenge [14]. In contrast, when serum Hp, SAA and AGP were evaluated under field conditions, serum concentrations of $\mathrm{Hp}$ were more useful in predicting the presence of respiratory disease and response to therapy, whereas SAA and AGP did not discriminate between animals which became sick and those that did not [21].

In the previous work, we demonstrated that phorbol ester stimulation of isolated peripheral blood neutrophils are is associated with appearance of Hp-MMP 9 complexes in culture medium within 30 minutes [22]. We also identified covalent, heteromeric complexes of $\mathrm{Hp}$ in complex with matrix metalloproteinase 9 (Hp-MMP 9), within the serum of cattle with clinically apparent acute onset of septic inflammation of the abdomen or thorax [23]. In these cases, sepsis was associated with the presence of Hp-MMP 9 complexes when serum was analyzed by ELISA. In contrast to free serum $\mathrm{Hp}$, whose main source is the liver during inflammation, serum Hp-MMP 9 complexes are only produced by neutrophils. As such, Hp-MMP 9 complexes, in serum, represent neutrophil degranulation [22].

Intravenous LPS injection has been shown to produce physiologic and biochemical alterations in cattle including increases in APP ( $\mathrm{Hp}[14,24]$, seromucoid [14], ceruloplasmin [14], $\alpha-1$ proteinase inhibitor [14], and SAA [24]), decreased feed intake [24-26], increased rectal temperature [24,25,27], dyspnea [24,26,27], increased cytokines (TNF $\alpha$ [24-27], IL-1 $\beta$ [27], IL-6 [27], and IFN- $\gamma$ [27]), increased cortisol [25,27]. We used this reproducible model to determine the time course of release of Hp-MMP 9 in comparison to other APP (Hp, SAA, AGP) after an acute LPS challenge.

As neutrophils play key roles in the early onset of bovine diseases, we sought to evaluate a biomarker specific to neutrophils for monitoring very early inflammation responses in cattle. The kinetics of most APP involves recognition of pathogens/pathogen products, mediator production and release, gene expression and protein synthesis and release of protein into the circulation [28-32]. Release of neutrophil granule proteins is rapid after in vitro stimulation, occurring within 30 minutes of phorbol ester treatment [22]. The objective of the present study was to characterize the time course of serum Hp-MMP 9 complex appearance in relation to changes in the hemogram, serum $C$ concentrations and by comparing with other acute phase proteins in calves (Hp, SAA, AGP).

We propose that Hp-MMP 9 complexes, observed after phorbol ester stimulation of isolated peripheral blood neutrophils in vitro and found in acute phase sera, have specific functional significance differing from un-complexed forms of Hp or MMP 9 alone and as a consequence, serum concentrations of Hp-MMP 9 may serve as an independent indicator of clinically important events occurring during acute inflammation.

\section{Methods}

\section{Experimental design}

The following experimental protocol was approved by The Ohio State University, Laboratory Animal Care and Use Committee. The study group consisted of 9 healthy Jersey bull calves between 65-82 days of age (average weight - $75 \pm 13 \mathrm{~kg}$; range - 58-100 kg), acclimated to grass hay and $0.7 \mathrm{~kg}$ mixed grain diet for 7 days prior to the start of the study. The calves were born at The Ohio 
State University, Waterman Dairy Farm and were transferred to our facility for use in these studies. Calves were housed in groups of 2 animals, with one group of 3 calves, in climate controlled stalls (average temperature $21.7^{\circ} \mathrm{C}$ ). Physical exams were performed daily throughout the study and body weights were monitored weekly. Twelve hours prior to LPS challenge, calves were fitted with indwelling jugular venous catheters ${ }^{\mathrm{a}}$ after clipping the hair and aseptic cleansing the skin using $1 \%$ iodine scrub followed by $70 \%$ isopropyl alcohol. A $30 \mathrm{~cm}$ extension line with infusion port was attached and the catheter was held in place with elastic tape. The catheter was flushed with heparinized saline. Blood was collected from the catheter for $\mathrm{CBC}$ and serum biochemical analysis. Serum was collected from clotted whole blood that was centrifuged at $2,000 \times \mathrm{g}$ for 20 minutes after clotting at room temperature. The serum was removed and stored at $-80^{\circ} \mathrm{C}$ until analysis.

At time $(\mathrm{T})=0$ hours, a physical exam was performed and blood was collected for a CBC and for serum collection which was stored for later analysis. All rectal temperature measurements were made using a digital thermometer. ${ }^{\text {b }}$ Lipopolysaccharide (LPS), ${ }^{\mathrm{c}} 2.5 \mu \mathrm{g} / \mathrm{kg}$ body weight, that was diluted in $10 \mathrm{ml}$ of autologous serum and allowed to incubate at $37^{\circ} \mathrm{C}$ for 30 minutes. After incubation, the LPS solution was administered rapidly via the IV catheter. After administration, each catheter was flushed with $10 \mathrm{~mL}$ heparinized saline $(10 \mathrm{IU} / \mathrm{mL})$. Physical exams and blood collection were performed at $\mathrm{T}=-24,0,0.5,1,1.5$, 2, 3, 4, 6, 8, 12, 16, 24, 36, 48, 72, $96 \mathrm{hr}$ post-LPS infusion. After each blood collection, equal volume of normal saline $(0.9 \% \mathrm{NaCl}$ for injection) was administered to maintain blood volume. IV catheters were removed after the last collection time point.

\section{Serum and blood analyses}

All serum analyses were performed using commercially available ELISA kits (Hp, SAA), single radial immunodiffusion (AGP, SRID) according to the manufacturers recommendations, whereas the Hp-MMP 9 ELISA is an in house laboratory assay. Serum $\mathrm{C}$ concentrations were determined by use of a solid phase, competitive chemiluminescent enzyme immunoassay and an automated analysis system as described ${ }^{\mathrm{d}}$ [33] by an accredited veterinary clinical pathology laboratory. Briefly, aliquots of each calf's serum were placed into individual test units for analysis. The calibration range of the assay is $28-1,380 \mathrm{nmol} / \mathrm{L}$ and analytical sensitivity is $5 \mathrm{nmol} / \mathrm{L}$. All samples from each calf were analyzed in a single run.

Serum total Hp was determined using a commercially available bovine Hp ELISA kit. The analysis was conducted according to the manufacturer's instructions. Specifically, all serum samples from all calves were diluted 1:2,000 in sample buffer prior to analysis. Serum concentrations were determined from the concentration vs. absorbance relationship of the standard haptoglobin concentrations $(7.8-250 \mathrm{ng} / \mathrm{mL})$. All calf serum sample concentrations were corrected for dilution (2,000 fold dilution). Analytical variation between samples on the same day and on multiple days is $<8.8$ and $12.9 \%$ respectively.

Bovine Hp-MMP 9 complexes were determined as described previously [23]. All serum samples were diluted 1:5 with sample diluent (TBS $+1 \%$ Bovine serum albumin $+0.05 \%$ Tween 20 . After blocking the wells, known concentrations of Hp-MMP 9 (serum, pre-characterized and shown to contain $~ 912.6 \mathrm{ng} / \mathrm{mL}$ Hp-MMP 9) and the LPS challenged calf serum samples were added to wells. If sample absorbance fell outside of the linear portion of the concentration-absorbance line, samples were further diluted to ensure linearity. Between plate variability of calibrators from 5 different plates were less than $3 \%$ (median $=1.8 \%$; range $0.98-2.7 \%$ ). The average coefficient of correlation determined from linear regression of the absorbance versus concentration of calibrator was 0.91 (range $0.85-0.95$ ). The analytical sensitivity of the assay is $3.5 \mathrm{ng} / \mathrm{mL}$.

Serum concentrations of SAA were determined using a commercial multi-species ELISA ("Phase" Serum Amyloid A assay ${ }^{f}$ ) used according to the manufacturer's instructions. All serum samples were diluted 1:500 with sample diluent buffer, and $50 \mu \mathrm{L}$ of sample or calibrator were added to each well containing the detection antibody and the absorbance determined on a plate reader. ${ }^{\mathrm{g}}$ The intra- and inter assay coefficients of variation for the assay were $<11 \%$ and the analytical sensitivity of the bovine assay is $0.3 \mu \mathrm{g} / \mathrm{mL}$.

Serum alpha ${ }_{1}$ acid-glycoprotein (AGP) concentrations were determined using a commercial single radial immuno-diffusion assay. ${ }^{\mathrm{h}}$ After addition of $5 \mu \mathrm{L}$ each, of AGP calibrators $(1,000 \mu \mathrm{g} / \mathrm{mL}, 250 \mu \mathrm{g} / \mathrm{mL}, 125 \mu \mathrm{g} / \mathrm{mL})$ and calf serum samples to individual wells on each plate, the plates were incubated for 48 hours in a humidified container at $37^{\circ} \mathrm{C}$. After incubation, the plates were imaged on a light table and the diameter of the rings measured using a 10x scale loupe with metric reticule. The diameter of precipitin rings of calibrators was plotted against the concentration of AGP to obtain an equation of the line. Repeated assay of the calibrators on 27 unique plates, produced coefficient's of variation between $2.7-3.5 \%$ over the range of the calibrators $(125-1000 \mu \mathrm{g} / \mathrm{mL})$, the average coefficient of correlation was 0.997 .

\section{Statistical analysis}

Data from the LPS challenge study (temperature, pulse, respiration, WBC count (total WBC, neutrophil counts, band neutrophil counts, lymphocyte counts) differential count, serum concentrations of C, Hp, Hp-MMP 9 complex, 
SAA, and AGP concentrations) were tabulated by time point and evaluated graphically in a commercial spreadsheet. ${ }^{i}$ After visual comparison of the data, the changes in physiologic variables (temperature, heart rate, respiration), number of peripheral white blood cells, differential counts (total WBC, PMN, band, lymphocyte) and concentrations of the analytes $(\mathrm{C}, \mathrm{Hp}, \mathrm{Hp}-\mathrm{MMP} 9$ complexes, SAA, AGP) over time were examined using PROC MIXED in SAS (v.9.3). To account for the correlated data structure of the repeated measures from individual calves over time, four covariance structures were tested (compound symmetry, first order autoregressive, heterogeneous first order autoregressive, and unstructured). Time was included in the model as the main variable of interest to evaluate how the different parameters changed in response to the LPS challenge. Baseline $(\mathrm{T}=0 \mathrm{hr}$ ) was used as the reference level and significance was set at $P \leq 0.05$. All measurements at different time-points were compared with the baseline value at $\mathrm{T}=0$. First order autoregressive covariance structure fitted the data best for SAA, AGP and C as outcomes, compound symmetry covariance structure was used with other outcomes. The areas under the concentration-time (AUC), for each acute phase protein analyte (Hp, Hp-MMP 9, SAA and AGP) were calculated using standard formulae, from time $=0$ to time $=96$ hours. No extrapolation of the terminal portion of the curve was conducted. The ratio of $\mathrm{AUC}_{\mathrm{Hp}-\mathrm{MMP}}{ }\left(\mathrm{ng} \mathrm{g}^{*} \mathrm{hr} / \mathrm{mL}\right)$, to each of the other analytes (Hp, SAA and AGP) were expressed as a percentage and compared using the Kruskal-Wallis, 1 way ANOVA on ranks with Dunn's multiple comparison test. Differences in ranks were considered significant when $\mathrm{p}<0.05$ for each comparison.

\section{Results}

The most consistent clinical indicators of illness were tachypnea and dyspnea developing within 30 minutes after LPS infusion $(\mathrm{p}<0.001$ in comparison to $\mathrm{T}=-24$ hours; Figure 1). Respiratory rates remained significantly greater than baseline until $4 \mathrm{~h}$ post-LPS and were not significantly greater than baseline by $6 \mathrm{~h}$ post-LPS $(\mathrm{p}=0.1542$; Figure 1). Changes in rectal temperature and heart rate in these calves were minimal and not significantly different from baseline (Figure 1). Significant changes in respiratory rate, occurred with a marked reduction in peripheral leukocytes and rapid increases in serum $C$ (Figure 1). Baseline serum $C$ concentrations were $27.6 \pm 7.8 \mathrm{nmol} / \mathrm{L}$ (range: $30-49.7 \mathrm{nmol} / \mathrm{L}$ ) at time $=0$ hours and peaked at $174 \pm 40 \mathrm{nmol} / \mathrm{L}$ (range: $102-254 \mathrm{nmol} / \mathrm{L}$ ) by 3 hours post-LPS infusion ( $<<0.0001$; Figure 1$)$. Total white blood cells (WBC), lymphocytes and neutrophil counts declined from baseline, reaching a nadir at 4 hours $(\mathrm{p}<0.0001)$ post-LPS (Figure 2). Total WBC returned to levels that were not different from baseline by $24-36$ hours

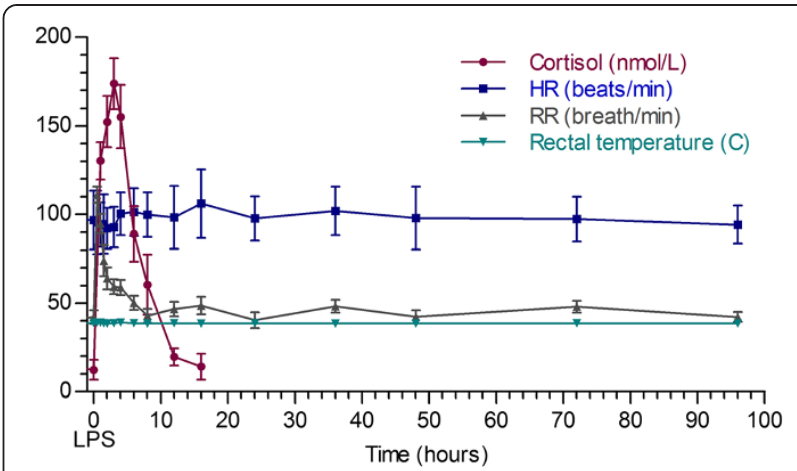

Figure 1 Mean \pm SD heart rate (beats/minute), respiratory rate (breaths/minute), rectal temperarture $\left({ }^{\circ} \mathrm{C}\right.$ ) and serum $\mathrm{C}$ concentrations ( $\mathrm{nmol} / \mathrm{L}$ ) observed after intravenous administration of $E$. coli LPS (0111:B4; 2.5 ug/kg solubilized in autologous serum). Statistically higher respiratory rates were observed by 0.5 hours post-LPS $(p<0.001)$ and remained higher than baseline ( -24 hour time point) until 6 hours post LPS infusion ( $p<0.0034)$. Serum $C$ values were significantly greater than baseline by 1 hour post LPS $(p<0.0001)$. There was no statistically significant change in the HR and RT for these calves.

post-LPS challenge (Figure 2). Peripheral neutropenia was associated with the appearance of "band" PMN at 8 hours $(0.2 \pm 0.36 \times 10$ [9]/L; range: $0-1.2 \times 10[9] / \mathrm{L} ; \mathrm{P}<0.0007$; data not shown) and remained significantly greater than baseline until 24 hours post LPS $(0.66 \pm 1.6 \times 10$ [9]/L; $\mathrm{p}<0.0001$ compared to baseline; data not shown). Other peripheral leukocyte types (monocytes, eosinophils, basophils) did not change significantly throughout the study period.

Administration of a single intravenous dose of LPS resulted in increased serum $\mathrm{Hp}$ concentrations. Serum concentrations of total $\mathrm{Hp}$ were $<10 \mu \mathrm{g} / \mathrm{mL}$ until 8 hours post-LPS infusion (Figure 3A), and increased to significantly

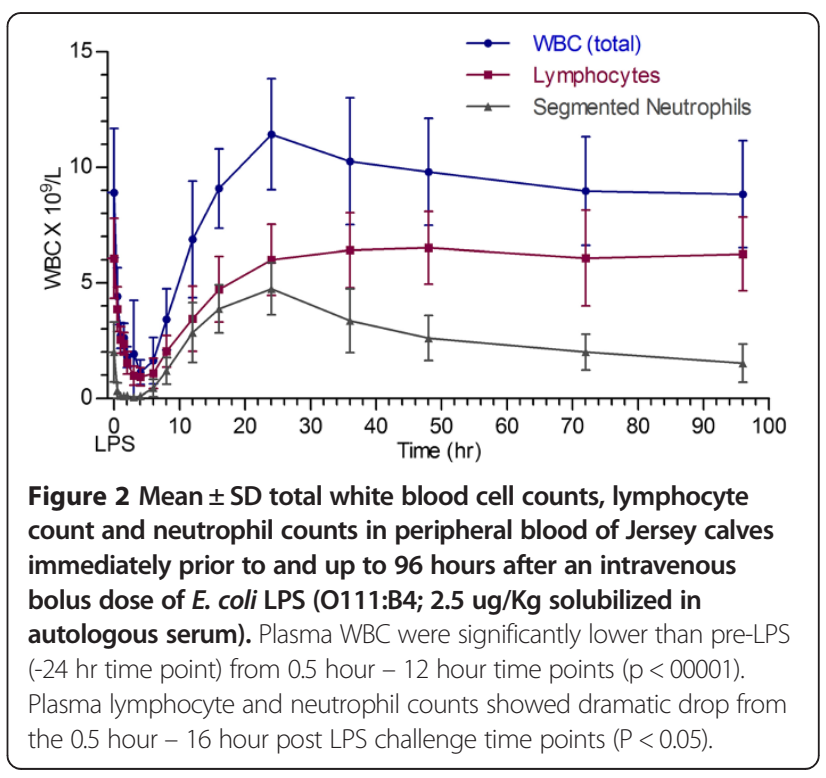




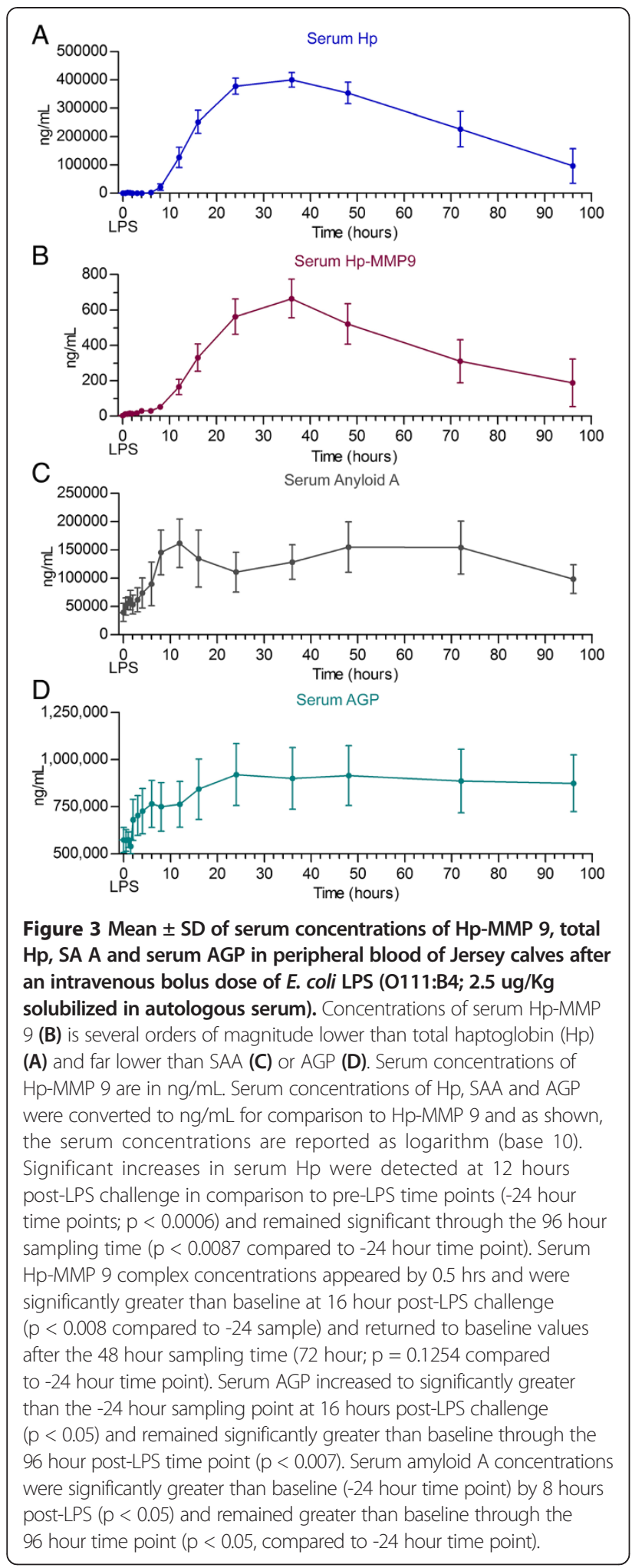

greater than baseline by 12 hours post-LPS infusion $(127 \pm 100 \mu \mathrm{g} / \mathrm{mL}$; range: $0-368 \mu \mathrm{g} / \mathrm{mL} ; \mathrm{p}=0.0006)$ (Figure 3A). Maximum serum concentrations of $\mathrm{Hp}$ were
$400 \pm 73 \mu \mathrm{g} / \mathrm{mL}$ (range: 257-460 $\mu \mathrm{g} / \mathrm{mL}$ ) 36 hours post-LPS infusion in all 9 experimental animals (Figure 3A). Serum concentrations of $\mathrm{Hp}$ remained significantly greater than baseline through the 96 hour time point $(\mathrm{p}=0.0087)$ in 2 of the nine calves; the remaining $7 / 9$ calves had serum haptoglobin $<30 \mu \mathrm{g} / \mathrm{mL}$ at the 96 hour time point. The increase in serum $\mathrm{Hp}$ concentrations occurred after resolution of clinical signs and was associated with return of serum $\mathrm{C}$ to baseline concentrations, increasing peripheral leukocyte counts.

Baseline concentrations of AGP were $591 \pm 124 \mu \mathrm{g} / \mathrm{mL}$ and did not change significantly until 16 hours postLPS challenge when serum AGP concentrations were $843 \pm 452 \mathrm{ug} / \mathrm{mL}(\mathrm{p}=0.0434)$ (Figure 3D). Serum AGP concentrations reached peak levels 24 hours post-LPS $(920 \pm 466 \mu \mathrm{g} / \mathrm{mL} ; \mathrm{p}=0.0065)$. Changes in serum AGP concentration also occurred after clinical signs and serum $\mathrm{C}$ concentrations returned to baseline and peripheral blood total WBC and neutrophil counts returned to baseline post LPS $(p<0.0001)$. Serum concentrations of AGP remained $>800 \mu \mathrm{g} / \mathrm{mL}$ throughout the remainder of the study period.

Serum concentrations of SAA responded to LPS challenge increasing from $29 \pm 35 \mu \mathrm{g} / \mathrm{mL}$ at baseline to $162 \pm 121 \mu \mathrm{g} / \mathrm{mL} ; 12 \mathrm{~h}$ post-LPS challenge; $\mathrm{p}=0.0049$ ), and remained significantly greater than baseline at 96 hours post-LPS infusion $(98.4 \pm 72 \mu \mathrm{g} / \mathrm{mL} ; \mathrm{p}=0.03)$ (Figure 3C). Like serum concentrations of $\mathrm{Hp}$ and AGP, changes in SAA were significantly greater than baseline by 8 hours and did not correspond to changes in clinical signs, serum $\mathrm{C}$ and peripheral WBC counts. Serum amyloid A concentrations peaked 12 hours post LPS, and remained above baseline concentrations through the end of the study.

Serum concentrations of Hp-MMP 9 complexes were detectable $(>3.5 \mathrm{ng} / \mathrm{mL})$ from $0.5-12$ hours post-LPS, although these values were not significantly different from baseline $(p=0.82)$ (Figure 3B). Serum concentrations of Hp-MMP 9 continued to increase until $36 \mathrm{hrs}$ post-challenge, reaching concentrations of $665 \pm 308 \mathrm{ng} / \mathrm{mL}$ (range 298-1311 ng/mL; p < 0.0001). Unlike the other APP markers (Hp, SAA, AGP), serum concentrations of Hp-MMP 9 decreased to concentrations that were not significantly different from baseline by 72 hours post-LPS infusion $(p=0.1254)$. Serum concentrations of Hp-MMP 9 were $<55 \mathrm{ng} / \mathrm{mL}$ in $7 / 9$ calves at 96 hours.

The average exposure (AUC), to LPS induced serum acute phase proteins demonstrated that exposure (concentration $\times$ time) to Hp-MMP 9 differed significantly from that of Hp $(\mathrm{p}<0.05)$ and AGP $(\mathrm{p}<0.001)$, but not SAA Figure 4). Area under the curve for Hp-MMP 9 $\left(\mathrm{AUC}_{\mathrm{Hp}-\mathrm{MMP}}\right.$ 9) was $0.14 \pm 0.05 \%$ of that for $\mathrm{Hp}$, $0.13 \pm 0.06 \%$ of that for SAA and $0.05 \pm 0.03 \%$ of that for AGP ( $\mathrm{P}<0.01$ for Hp-MMP 9 compared to Hp and AGP 


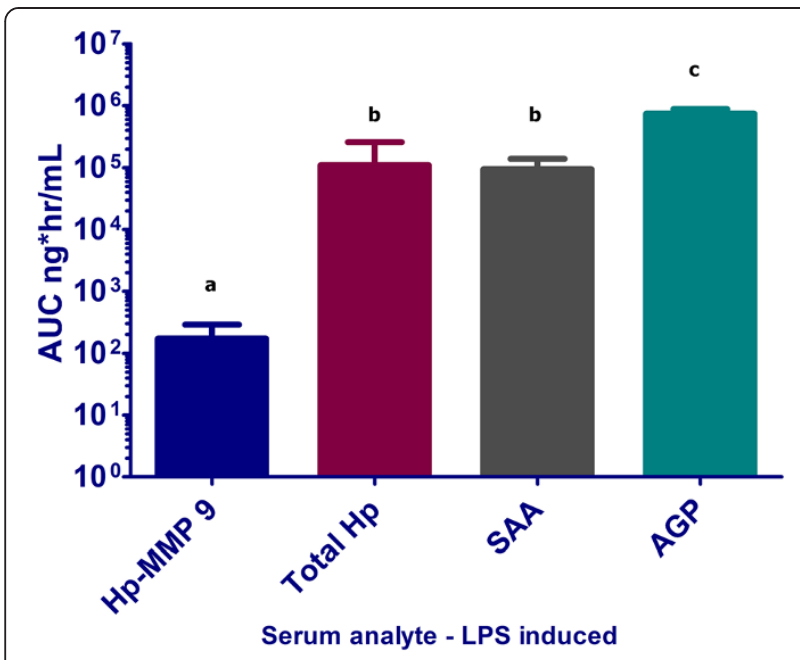

Figure 4 Total systemic exposure of animal to serum acute phase proteins. Serum concentrations of serum acute phase proteins over time were converted to $\mathrm{ng} / \mathrm{mL}$ and the area under the curve was calculated using the trapezoidal rule. Data for each analyte are reported as $\mathrm{AUC}_{0-96} \mathrm{hr}$ and plotted on log-linear graph. Area under the curve of serum Hp-MMP 9 was significantly lower than all 3 other serum acute phase proteins $(p<0.01)$ when evaluated using Kruskal-Wallis, 1 way ANOVA on ranks with Dunn's multiple comparison test. There was no significant difference between total serum $\mathrm{Hp}$ and SAA over the time course of analysis and both $\mathrm{SAA}$ and $\mathrm{Hp}$ had significantly lower exposure in comparison to the areas observed for AGP. Differences in the letters over bars indicate significant differences between AUC for each analyte.

responses; Figure 4). The $\mathrm{AUC}_{\mathrm{AGP}}$ was significantly greater than $\mathrm{AUC}_{\mathrm{SAA}}(\mathrm{p}<0.01)$.

\section{Discussion}

The purpose of this study was to evaluate the time course of a neutrophil biomarker (Hp-MMP 9 complexes) after LPS challenge in calves in comparison to responses of established serum APP markers in cattle. Using a single challenge stimulus producing consistent clinical, hematologic, physiologic and APP responses, the concentration versus time profile of this neutrophil biomarker may prove useful to define the activation of neutrophils early in the course of inflammation. While not fully replicating the major clinical and pathologic findings associated with natural BRD, the characteristics of the LPS stimulus should allow dissection of neutrophil from other APP responses occurring in inflammation $[27,34,35]$. In clinical terms, we believe early and specific detection of neutrophil activation should provide an indication of early responses to infection. Further, this response is distinct from that of the liver [36].

Bovine neutrophils have been shown to play key roles in host responses to infection [34]. Experimental bacterial pneumonia models have demonstrated rapid recruitment of neutrophils to the lung is associated with tachypnea, dyspnea, hypercortisolemia, peripheral leukopenia and influx of neutrophils into the lungs [27,34,35,37-40]. Our previous studies demonstrated a unique form of neutrophil matrix-metalloproteinase 9, covalently linked to haptoglobin (Hp-MMP 9) are stored in and released by neutrophils; and these complexes are present within the serum of cattle with acute, polymicrobial sepsis $[22,23]$. Therefore, as a unique marker produced by the neutrophil, serum Hp-MMP 9 complexes should herald early changes in neutrophils associated with the host response to inflammation.

Both natural and experimental infection studies demonstrate the appearance of APP supporting their use in detection of inflammation and response to therapy $[1,14,18,19,21,24,41-47]$. Although some APP have proven useful in the evaluation of illness in cattle, their contributions to the bovine serum acute phase response, represent contributions of hepatocytes or other tissues in response to proximate mediators produced by other cells $[1,14,44,45]$. Timing of APP responses vary by APP marker and do not necessarily represent events occurring in the sub-clinical phase of disease such as when changes in clinical signs, serum $C$ and peripheral leukopenia occur. Upon activation, peripheral blood neutrophils are a source of many proteins, including matrix metalloproteinase 9, Hp and AGP. These neutrophil APP in serum are a part of the acute phase proteome; however, current assays do not identify sources of these proteins [48-50].

As a component of neutrophil granules, Hp-MMP 9 should not be present within the circulation of healthy animals and prior studies demonstrated Hp-MMP 9 was not present in the serum of healthy cows [23]. After an intravenous dose of LPS, serum concentrations of Hp-MMP 9 were above the limit of detection of our ELISA $(>3.5 \mathrm{ng} / \mathrm{mL})$ by 1 hour. Serum Hp-MMP 9 complexes are detected when changes in respiratory rate, serum $\mathrm{C}$ and WBC numbers occur. We have also demonstrated cattle undergoing experimental bacterial pneumonia and naturally occurring cases of acute poly-microbial sepsis were associated with increased serum concentrations of Hp-MMP 9 complexes [23,24]. Experimental bacterial infection is associated with lung lesions consistent with Mannheimia hemolytica infection in these calves and with rapid increases in serum concentrations of Hp and Hp-MMP 9 complexes [51]. Similarly, transportation is associated with increased incidence of respiratory disease and $\mathrm{Hp}$ is proposed to be a marker of non-inflammatory stress $[52,53]$. Stress induced induction of serum $\mathrm{Hp}$ still involves release of production of cytokines and hepatic expression of $\mathrm{Hp}$ and other APP. [53] A recent study demonstrated the appearance of Hp-MMP 9 in serum after transportation suggesting transportation stress is also associated with measurable responses of neutrophils [52,54]. These studies support the further evaluation of Hp-MMP 9 complex as a marker of early inflammation. 
Both neutrophil Hp-MMP 9 and SAA showed rapid increases in serum concentrations in LPS challenged calves, consistent with earlier studies $[1,19,45,55]$. However, individual calf data for SAA varied somewhat, making them significantly different from baseline only by 8 hours postLPS. However, serum Hp-MMP 9, and SAA concentrations observed after LPS challenge increased concurrently with onset of tachypnea, peak serum $\mathrm{C}$ concentrations and reduction of circulating leukocytes. Our results are consistent with these findings; however, we observed sustained SAA concentrations to at least 96 hours post-LPS challenge $[1,19,27,43,45,55,56]$. Other studies conducting i.v. LPS challenge, characterized the induction of SAA out to 10 hours post-challenge $[1,27,45]$. Prolonged elevations of SAA observed in our study suggest continued production after LPS stimulation. It is plausible then, that use of SAA in animals may be useful in diagnosis of acute inflammation. However, most of the SAA produced in association with LPS-induced inflammation also represents hepatic responses [56].

In contrast, the clinical, hematologic and $\mathrm{C}$ responses occurring in our calves after intravenous LPS challenge preceded increased serum $\mathrm{Hp}$ and AGP concentrations by several hours. Serum Hp concentrations remained normal until 8 hours; however, 5/9 had no detectable Hp until 12 hours post LPS challenge. Similarly, serum AGP concentrations were observed to increase significantly at 16 hours post LPS. As previous studies demonstrate, serum Hp and AGP concentrations remain significantly greater than baseline until the end of the study period, well after the LPS induced changes in respiratory function, serum $C$ and leukopenia had resolved [18-20]. Like Hp, Hp-MMP 9, AGP is also produced by bovine neutrophils [49]. It is plausible that serum AGP concentrations as detected with currently available methods may reflect contributions from the neutrophil. However, these methods do not specifically identify this form autonomously of others present.

Serum APP terminal half-life is been proposed to be useful in terms of effectiveness of empirical antimicrobial therapy for pneumonia in humans [57]. The serum concentration versus time profile of Hp-MMP 9 (AUC) was smaller than that of other APP measured. Area's under the Hp-MMP 9, concentration-time curve $\left(\mathrm{AUC}_{\mathrm{HP}-\mathrm{MMP}}\right.$ 9) in our calves were $0.14 \%$ of that measured for serum total $\mathrm{Hp}\left(\mathrm{AUC}_{\mathrm{HP}}\right), 0.13 \%$ of $\mathrm{AUC}_{\mathrm{SAA}}$ and $0.05 \%$ of $\mathrm{AUC}_{\mathrm{AGP}}$. This suggests that the animal's exposure to Hp-MMP 9 is much lower than that for Hp, SAA and AGP. This seems plausible since neutrophils and their granule proteins are limited in comparison to hepatic APP induced by inflammatory mediators. Characterization of the elimination processes of each APP may help to define the half-life of these proteins after induction. This information may provide a means for evaluation of the rate of normalization associated with therapy.

\section{Conclusions}

As Hp-MMP 9 is detectable early after a consistent inflammatory stimulus when animals develop clinical signs, we believe that like SAA, it may serve as a useful marker of early inflammation. The serum content of this neutrophil protein complex induced by inflammation is limited in extent and is masked by APP produced by the liver. Dissecting the contribution of the neutrophil to the APP responses produced by other sources may prove useful as an adjunct to the clinical examination after arrival at the feedlot, for pre-slaughter exams and other situations. The availability of a test providing objective data regarding the status of the neutrophil, so intimately involved in acute inflammation, may have potential in clinical algorithms and decision making used in diseased cattle.

\section{Endnotes}

${ }^{a}$ Angiocath, 16GA, 3.5 inch; Becton Dickinson, Sandy, Utah

${ }^{\mathrm{b}}$ GLA M700 Digital Thermometer; GLA Agricultural electronics, San Luis Obispo, CA 93401

${ }^{\mathrm{c}}$ Escherichia coli O111:B4; L2630 Sigma-Aldrich, St. Louis, MO.

${ }^{\mathrm{d}}$ IMMULITE 1000 Cortisol, Immunoassay system. DPS, Los Angeles, CA

${ }^{\mathrm{e}}$ Life diagnostics, Haptoglobin ELISA test kit; catalogue \#2410-7. West Chester, PA 19380; www.lifediagnostics. com

${ }^{\mathrm{f}}$ Multispecies Cat no. TP-802; Tri-Delta Development LTD, Kildare, Ireland

${ }^{\mathrm{g}}$ Labsystems, Multiskan MS; P97180; Vienna, VA, 22182

${ }^{\mathrm{h}}$ Cardiotech services, P0101-1; Louisville KY 40205

${ }^{\mathrm{i}}$ Microsoft Excel, Microsoft, Corp. Redmond, WA 98052-6399

${ }^{j}$ SAS, Version 9.2, SAS Institute, Cary NC 27513-2414; www.sas.com

\section{Abbreviations}

AGP: Alpha 1 acid-glycoprotein; ANOVA: Analysis of variance; APP: Acute phase protein; AUC: Area under the curve; BRD: Bovine respiratory disease; C: Cortisol; ELISA: Enzyme linked immunosorbent assay; Hp: Serum total haptoglobin concentration; Hp-MMP 9: Hp in complex with matrix metalloproteinase 9; LPS: Lipopolysaccharide; NaCl: 0.9\% sodium chloride for injection; PMN: Neutrophil; SAA: Serum amyloid A; TBS: Tris buffered saline; WBC: White blood cell.

\section{Competing interests}

The authors declare that they have no competing interests as we have not received reimbursements, fees, funding, or salary from any organization that may in any way gain or lose financially from the publication of this manuscript, either now or in the future. We declare owning no stocks or shares in any organization that may gain or lose financially from the publication of this manuscript. While we filed a patent with the USPTO, the application was placed on inactive status. 


\section{Authors' contributions}

$\mathrm{CAH}$ - designed the study, got approval for the use of animals in this study from the Institutional animal care and use committee of The Ohio State University, acquired the animals and conducted the experimental phase of the project. He collected the specimens, performed the ELISA assays for haptoglobin and Hp-MMP 9 in the laboratory, collected the data and discussed analysis with the statistician, wrote the manuscript, revised it after review. AJN - assisted with design and conduct of the study, and critically evaluated the manuscript. CP - assisted with design of experiments and writing the manuscript. PJRS - assisted with design of the study, analyzed the data and assisted with manuscript preparation and revision. DMR - assisted with study design, examined the animals prior to and during the study, assisted with preparation and revision of the submitted manuscript. $J \mathrm{~L}$ - conceived the study and selected analytical endpoints, assisted with analysis of the serum samples for Hp, Hp-MMP 9, analyzed the serum samples for SAA, AGP and C, preparation of the LPS for administration, assisted with critical evaluation and revision of the manuscript. All authors read and approved the final manuscript.

\section{Acknowledgements}

Supported by a grant from the USDA, NIFA AFRI 2008-35204-04473. This manuscript represents a portion of a thesis submitted by Dr. Hinds to the Ohio State University, Department of Veterinary Clinical Sciences as partial fulfillment of the requirements for a Master of Science degree.

\section{Author details}

${ }^{1}$ Department of Veterinary Clinical Sciences, College of Veterinary Medicine, The Ohio State University, 601 Vernon L Tharp Street, Columbus, Ohio 43210, USA. ${ }^{2}$ Department of Veterinary Biosciences, College of Veterinary Medicine, The Ohio State University, 1900 Coffey Road, Columbus, Ohio 43210, USA. ${ }^{3}$ Department of Veterinary Preventive Medicine, College of Veterinary Medicine, The Ohio State University, 1900 Coffey Road, Columbus, Ohio 43210, USA. ${ }^{4}$ Current address: University of Idaho, Caine Veterinary Teaching Center, 1020 East Homedale Road, Caldwell, ID 83607, USA.

Received: 21 May 2014 Accepted: 17 October 2014

Published online: 30 October 2014

\section{References}

1. Werling D, Sutter F, Arnold M, Kun G, Tooten PC, Gruys E, Kreuzer M, Langhans W: Characterisation of the acute phase response of heifers to a prolonged low dose infusion of lipopolysaccharide. Res Vet Sci 1996, 61:252-257.

2. Smith RA: Impact of disease on feedlot performance: a review. J Anim Sci 1998, 76:272-274.

3. United States Department of Agriculture: Cattle On Feed. Available at: http://www.nass.usda.gov/. Accessed Sep 28, 14 A.D.

4. Wittum TE, Young CR, Stanker LH, Griffin DD, Perino LJ, Littledike ET: Haptoglobin response to clinical respiratory tract disease in feedlot cattle. Am J Vet Res 1996, 57:646-649.

5. Humblet MF, Coghe J, Lekeux P, Godeau JM: Acute phase proteins assessment for an early selection of treatments in growing calves suffering from bronchopneumonia under field conditions. Res Vet Sci 2004, 77:41-47.

6. Katoh $\mathrm{N}$, Nakagawa $\mathrm{H}$ : Detection of haptoglobin in the high-density lipoprotein and the very high-density lipoprotein fractions from sera of calves with experimental pneumonia and cows with naturally occurring fatty liver. J Vet Med Sci 1999, 61:119-124.

7. Morimatsu M, Syuto B, Shimada N, Fujinaga T, Yamamoto S, Saito M, Naiki M: Isolation and characterization of bovine haptoglobin from acute phase sera. J Biol Chem 1991, 266:11833-11837.

8. Gozho GN, Plaizier JC, Krause DO, Kennedy AD, Wittenberg KM: Subacute ruminal acidosis induces ruminal lipopolysaccharide endotoxin release and triggers an inflammatory response. J Dairy Sci 2005, 88:1399-1403.

9. Nielsen BH, Jacobsen S, Andersen PH, Niewold TA, Heegaard PM: Acute phase protein concentrations in serum and milk from healthy cows, cows with clinical mastitis and cows with extramammary inflammatory conditions. Vet Rec 2004, 154:361-365.

10. Ohtsuka H, Kudo K, Mori K, Nagai F, Hatsugaya A, Tajima M, Tamura K, Hoshi F, Koiwa M, Hawamura S: Acute phase response in naturally occurring coliform mastitis. J Vet Med Sci 2001, 63:675-678.
11. Stengarde L, Traven M, Emanuelson U, Holtenius K, Hultgren J, Niskanen R: Metabolic profiles in five high-producing Swedish dairy herds with a history of abomasal displacement and ketosis. Acta Vet Scand 2008, 50:31.

12. Arthington JD, Eichert SD, Kunkle WE, Martin FG: Effect of transportation and commingling on the acute-phase protein response, growth, and feed intake of newly weaned beef calves. J Anim Sci 2003, 81:1120-1125.

13. Murata $\mathrm{H}$, Miyamoto T: Bovine haptoglobin as a possible immunomodulator in the sera of transported calves. Br Vet J 1993 149:277-283.

14. Conner JG, Eckersall PD, Wiseman A, Bain RK, Douglas TA: Acute phase response in calves following infection with Pasteurella haemolytica, Ostertagia ostertagi and endotoxin administration. Res Vet Sci 1989, 47:203-207.

15. Conner JG, Eckersall PD, Wiseman A, Aitchison TC, Douglas TA: Bovine acute phase response following turpentine injection. Res Vet Sci 1988, 44:82-88.

16. Eckersall PD, Young FJ, McComb C, Hogarth CJ, Safi S, Weber A, McDonald T, Nolan AM, Fitzpatrick JL: Acute phase proteins in serum and milk from dairy cows with clinical mastitis. Vet Rec 2001, 148:35-41.

17. Hiss S, Mielenz M, Bruckmaier RM, Sauerwein H: Haptoglobin concentrations in blood and milk after endotoxin challenge and quantification of mammary Hp mRNA expression. J Dairy Sci 2004 87:3778-3784

18. Berry BA, Confer AW, Krehbiel CR, Gill DR, Smith RA, Montelongo M: Effects of dietary energy and starch concentrations for newly received feedlot calves: II. Acute-phase protein response. J Anim Sci 2004, 82:845-850.

19. Horadagoda A, Eckersall PD, Hodgson JC, Gibbs HA, Moon GM: Immediate responses in serum TNF alpha and acute phase protein concentrations to infection with Pasteurella haemolytica A1 in calves. Res Vet Sci 1994, 57:129-132.

20. Alsemgeest SP, Kalsbeek HC, Wensing T, Koeman JP, van Ederen AM, Gruys E: Concentrations of serum amyloid-A (SAA) and haptoglobin (HP) as parameters of inflammatory diseases in cattle. VetQ 1994, 16:21-23.

21. Carter JN, Meredith GL, Montelongo M, Gill DR, Krehbiel CR, Payton ME, Confer AW: Relationship of vitamin E supplementation and antimicrobial treatment with acute-phase protein responses in cattle affected by naturally acquired respiratory tract disease. Am J Vet Res 2002, 63:1111-1117.

22. Bannikov GA, Mattoon JS, Abrahamsen EJ, Premanandan C, Green-Church KB, Marsh AE, Lakritz J: Biochemical and enzymatic characterization of purified covalent complexes of matrix metalloproteinase- 9 and haptoglobin released by bovine granulocytes in vitro. Am J Vet Res 2007, 68:995-1004.

23. Bannikov GA, Hinds CA, Rajala-Schultz PJ, Premanandan C, Rings DM, Lakritz J: Serum haptoglobin-matrix metalloproteinase 9 (Hp-MMP 9) complex as a biomarker of systemic inflammation in cattle. Vet Immunol Immunopathol 2011, 139:41-49.

24. Kahl S, Elsasser TH: Exogenous testosterone modulates tumor necrosis factor-alpha and acute phase protein responses to repeated endotoxin challenge in steers. Domest Anim Endocrinol 2006, 31:301-311.

25. Steiger M, Senn M, Altreuther G, Werling D, Sutter F, Kreuzer M, Langhans W: Effect of a prolonged low-dose lipopolysaccharide infusion on feed intake and metabolism in heifers. J Anim Sci 1999, 77:2523-2532.

26. Waldron MR, Nishida T, Nonnecke BJ, Overton TR: Effect of lipopolysaccharide on indices of peripheral and hepatic metabolism in lactating cows. J Dairy Sci 2003, 86:3447-3459.

27. Carroll JA, Reuter RR, Chase CC Jr, Coleman SW, Riley DG, Spiers DE, Arthington JD, Galyean ML: Profile of the bovine acute-phase response following an intravenous bolus-dose lipopolysaccharide challenge. Innate Immun 2009, 15:81-89.

28. Hocke GM, Barry D, Fey GH: Synergistic action of interleukin-6 and glucocorticoids is mediated by the interleukin- 6 response element of the rat alpha 2 macroglobulin gene. Mol Cell Biol 1992, 12:2282-2294.

29. Dinarello CA: Infection, fever, and exogenous and endogenous pyrogens: some concepts have changed. J Endotoxin Res 2004, 10:201-222.

30. Van Miert AS, Van Duin CT, Koot M: Effects of E. coli endotoxin, some interferon-inducers, recombinant interferon- alpha 2a and Trypanosoma brucei infection on feed intake in dwarf goats. J Vet Pharmacol Ther 1990, 13:327-331

31. Baumann H, Gauldie J: The acute phase response, Immunol. Today 1994 , 15:74-80. 
32. Nakajima $Y$, Momotani E, Murakami T, Ishikawa $Y$, Morimatsu M, Saito M, Suzuki H, Yasukawa K: Induction of acute phase protein by recombinant human interleukin-6 (IL-6) in calves. Vet Immunol Immunopathol 1993, 35:385-391.

33. Baldridge SL, Coetzee JF, Dritz SS, Reinbold JB, Gehring R, Havel J, Kukanich B: Pharmacokinetics and physiologic effects of intramuscularly administered xylazine hydrochloride-ketamine hydrochloride-butorphanol tartrate alone or in combination with orally administered sodium salicylate on biomarkers of pain in Holstein calves following castration and dehorning. Am J Vet Res 2011, 72:1305-1317.

34. Slocombe RF, Malark J, Ingersoll R, Derksen FJ, Robinson NE: Importance of neutrophils in the pathogenesis of acute pneumonic pasteurellosis in calves. Am J Vet Res 1985, 46:2253-2258.

35. Constable PD, Schmall LM, Muir WW III, Hoffsis GF: Respiratory, renal, hematologic, and serum biochemical effects of hypertonic saline solution in endotoxemic calves. Am J Vet Res 1991, 52:990-998.

36. Griffin DD: Respiratory Disease Treatment Considerations in Feedyards. In Current Veterinary Therapy, Food Animal Practice. Edited by Anderson DE, Rings DM. St. Louis, MO: Saunders/Elsevier; 2009:509-519.

37. Radi ZA, Caverly JM, Dixon RA, Brogden KA, Ackermann MR: Effects of the synthetic selectin inhibitor TBC1269 on tissue damage during acute Mannheimia haemolytica-induced pneumonia in neonatal calves. Am J Vet Res 2001, 62:17-22.

38. Radi ZA, Brogden KA, Dixon RA, Gallup JM, Ackermann MR: A selectin inhibitor decreases neutrophil infiltration during acute Mannheimia haemolytica pneumonia. Vet Pathol 2002, 39:697-705.

39. Caverly JM, Radi ZA, Andreasen CB, Dixon RA, Brogden KA, Ackermann MR: Comparison of bronchoalveolar lavage fluid obtained from Mannheimia haemolytica-inoculated calves with and without prior treatment with the selectin inhibitor TBC1269. Am J Vet Res 2001, 62:665-672.

40. Constable PD, Schmall LM, Muir WW III, Hoffsis GF, Shertel ER: Hemodynamic response of endotoxemic calves to treatment with small-volume hypertonic saline solution. AmJVetRes 1991, 1(52):981-989.

41. Lafleur RL, Malazdrewich C, Jeyaseelan S, Bleifield E, Abrahamsen MS, Maheswaran SK: Lipopolysaccharide enhances cytolysis and inflammatory cytokine induction in bovine alveolar macrophages exposed to Pasteurella (Mannheimia) haemolytica leukotoxin. Microb Pathog 2001, 30:347-357

42. Kinsbergen M, Bruckmaier RM, Blum JW: Metabolic, endocrine and haematological responses to intravenous $E$. coli endotoxin administration in 1-week-old calves. Zentralb/ Veterinarmed A 1994, 41:530-547.

43. Petersen $\mathrm{HH}$, Nielsen JP, Heegaard PM: Application of acute phase protein measurements in veterinary clinical chemistry. Vet Res 2004, 35:163-187.

44. Godson DL, Campos M, Attah-Poku SK, Redmond MJ, Cordeiro DM, Seth MS, Harland RJ, Babiuk LA: Serum haptoglobin as an indicator of the acute phase response in bovine respiratory disease. Vet Immunol Immunopathol 1996, 51:277-292.

45. Carroll JA, Burdick NC, Reuter RR, Chase CC, Spiers DE, Arthington JD, Coleman SW: Differential acute phase immune responses by Angus and Romosinuano steers following an endotoxin challenge. Domest Anim Endocrinol 2011, 41:163-173.

46. Hsuan SL, Kannan MS, Jeyaseelan S, Prakash YS, Malazdrewich C, Abrhamsen MS, Sieck GC, Maheswaran SK: Pasteurella haemolytica leukotoxin and endotoxin induced cytokine gene expression in bovine alveolar macrophages requires NF-kappaB activation and calcium elevation. Microb Pathog 1999, 26:263-273.

47. Malazdrewich C, Thumbikat P, Abrahamsen MS, Maheswaran SK. Pharmacological inhibition of Mannheimia haemolytica lipopolysaccharide and leukotoxin-induced cytokine expression in bovine alveolar macrophages. Microb Pathog 2004, 36:159-169.

48. Cooray R, Waller KP, Venge P: Haptoglobin comprises about $10 \%$ of granule protein extracted from bovine granulocytes isolated from healthy cattle. Vet Immunol Immunopathol 2007, 119:310-315.

49. Rahman MM, Miranda-Ribera A, Lecchi C, Bronzo V, Sartorelli P, Franciosi F, Ceciliani F: Alpha(1)-acid glycoprotein is contained in bovine neutrophil granules and released after activation. Vet Immunol Immunopathol 2008, 125:71-81.

50. Li X, Zhao $X$, Ma S: Secretion of 92 kDa gelatinase (MMP-9) by bovine neutrophils. Vet Immunol Immunopathol 1999, 67:247-258.

51. Theurer ME, Anderson DE, White BJ, Miesner MD, Mosier DA, Coetzee JF, Lakritz J, Amrine DE: Effect of Mannheimia haemolytica pneumonia on behavior and physiologic responses of calves during high ambient environmental temperatures. J Anim Sci 2013, 91:3917-3929.

52. Cernicchiaro N, White BJ, Renter DG, Babcock AH, Kelly L, Slattery R: Associations between the distance traveled from sale barns to commercial feedlots in the United States and overall performance, risk of respiratory disease, and cumulative mortality in feeder cattle during 1997 to 2009. J Anim Sci 2012, 90:1929-1939.

53. Murata $\mathrm{H}$ : Stress and acute phase protein response: an inconspicuous but essential linkage. Vet J 2007, 173:473-474

54. Van Engen NK, Stock ML, Engelken T, Vann RC, Wulf LE, Karriker LA, Busby WD, Lakritz J, Carpenter AJ, Bradford BJ, Hsu WH, Wang C, Coetzee JF: Impact of oral meloxicam on circulating physiological biomarkers of stress and inflammation in beef steers after long-distance transportation. J Anim Sci 2014, 92:498-510.

55. Horadagoda NU, Knox KM, Gibbs HA, Reid SW, Horadagoda A, Edwards SE, Eckersall PD: Acute phase proteins in cattle: discrimination between acute and chronic inflammation. Vet Rec 1999, 144:437-441.

56. Eckersall PD: Proteomics and the dysproteinemias. In Clinical Biochemistry of Domestic Animals. 6th edition. Edited by Kaneko JJ, Harvey JW, Bruss ML. Boston, MA: Academic Press; 2014:117-155.

57. Takata S, Wada H, Tamura M, Koide T, Higaki M, Mikura SI, Yasutake T, Hirao S, Nakamura M, Honda K, Nagatomo T, Tanaka Y, Schara E, Watanabe M, Yokoyama T, Saraya T, Kurai D, Ishii H, Goto H: Kinetics of c-reactive protein (CRP) and serum amyloid A protein (SAA) in patients with community-acquired pneumonia (CAP), as presented with biologic half-life times. Biomarkers 2011, 16:530-535.

doi:10.1186/s12917-014-0261-0

Cite this article as: Hinds et al:: Characterization of the contributions of Hp-MMP 9 to the serum acute phase protein response of lipopolysaccharide challenged calves. BMC Veterinary Research 2014 10:261.

\section{Submit your next manuscript to BioMed Central and take full advantage of:}

- Convenient online submission

- Thorough peer review

- No space constraints or color figure charges

- Immediate publication on acceptance

- Inclusion in PubMed, CAS, Scopus and Google Scholar

- Research which is freely available for redistribution 